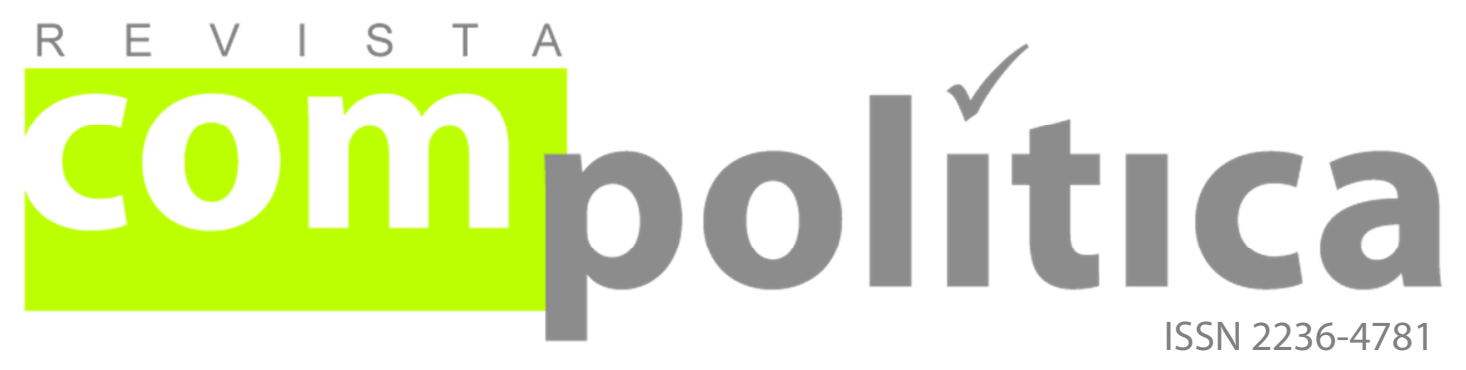

\title{
PRUDÊNCIO, Kelly
}

Docente no Programa de Pós-Graduação em Comunicação na UFPR. Coordenadora do grupo de pesquisa Comunicação e Mobilização Política.

<kelly.prudencio5@gmail.com>

\section{Micromobilizações, alinhamento de quadros e comunicação política}

RESUMO

A proposta do artigo é discutir as micromobilizações na internet pela perspectiva da teoria da mobilização política. Para isso, serão apresentados confrontos políticos a partir de seus processos de alinhamento de quadros: confrontos com o Estado e confrontos entre grupos na internet nos anos de 2012 e 2013. Foi possível perceber que o primeiro tipo de confronto produz uma comunicação política mais efetiva enquanto o segundo é mais interessante para fortalecer os vínculos entre os atores envolvidos. As micromobilizações são analisadas a partir da interpretação dos enquadramentos da ação coletiva, tendo como pressuposto que o repertório desses grupos mobilizados é o recurso através do qual se estabelece a comunicação política atualmente, fortemente perpassada pelo ativismo digital.

Palavras-chave: micromobilização, comunicação, enquadramento.

\section{ABSTRACT}

This paper discusses the micromobilizations on the internet from the perspective of the theory of political mobilization. Frame alignment processes of contention politics are presented: confrontations against the State and clashes between groups on the Internet in the years 2012 and 2013. It can be seen that the first kind of confrontation produces a more effective political communication as the second is more interesting to strengthen the links between the actors. The micromobilizations are analyzed from the interpretation of frames of collective action, with the assumption that the repertoire of these mobilized groups is the feature through which political communication occurs today, strongly permeated by digital activism.

Keywords: micromobilization, communication, frames. 


\section{Micromobilizações, alinhamento de quadros e comunicação política}

\section{[Micromobilizations, frame alignment processes and political communication]}

PRUDÊNCIO, Kelly

O

interesse pela mobilização de atores sociais na internet cresce juntamente com a quantidade de protestos, vídeos virais, campanhas, "tuitaços" e outras práticas que se tornam cada vez mais comuns nas redes sociais digitais. Porém, há algum tempo, pesquisadores têm mostrado que a participação política não aumenta por causa da internet (Rucht, 2004; Maia e Gomes, 2011; Prudencio, 2010, 2013).

O que se tem visto na internet em termos de ativismo digital está menos relacionado a grandes causas de movimentos sociais e mais a campanhas específicas, cujas marcas são as hashtags e o compartilhamento de conteúdo informativo para mobilizar quadros de atores coletivos e individuais. Por essa razão, na perspectiva da teoria da mobilização política, torna-se mais apropriado falar em micromobilizações. "Micromobilização" é um termo cunhado por Snow et al (1986, p.465) para se referir "ao conjunto de processos interativos elaborados e empregados pelas $\mathrm{OMS}^{1}$ e por seus representantes para mobilizar ou influenciar outros grupos na busca de interesses coletivos ou comuns".

Assim, esse conceito é recuperado para interpretar o ativismo na internet. Quase três décadas depois da publicação do artigo, observase a emergência de outras formas de ação mais fluidas, o que se deve

\footnotetext{
${ }^{1}$ Organizações de movimentos sociais.
} 
em larga medida pela consolidação de práticas de ação coletiva com a utilização de tecnologias digitais.

o que está em jogo nestas micromobilizações é o sentido de determinados aspectos da realidade social para os atores envolvidos e a possibilidade de exercer influência sobre eles. Atuando sobre este sentido está o trabalho de alinhamento de quadros que ativistas operacionalizam na tentativa de comunicar seus "quadros da ação coletiva" (collective action frames) os quais abarcam conjuntos de crenças e significados e são capazes de inspirar e legitimar nos indivíduos o impulso do agir coletivo (Snow \& Benford, 2000, p.614).

Para isso, serão apresentados dois processos de confronto político: confrontos com o Estado e confrontos entre grupos com disputas de enquadramento na internet nos anos de 2012 e 2013.

No confronto político com o Estado, foram identificadas as micromobilizações do Movimento pelo Passe Livre (1), catalisador inicial das grandes mobilizações nas ruas do Brasil em junho de 2013; (2) o embate estabelecido em torno do programa do governo federal Mais Médicos; e o embate sobre a realização da Copa do Mundo de Futebol da $\operatorname{FIFA}^{2}(3)$. Nessas o confronto situa-se basicamente na oposição dos grupos com o governo ou política de Estado. O repertório na internet é marcado por hashtags no Twitter e no Facebook para indicar posições contrárias ou favoráveis, com pouca argumentação e ausência da participação de agentes do sistema político.

O confronto entre grupos é o que mais encontra lugar para uma disputa de enquadramentos, pois não está restrito à contestação de uma política ou um programa do governo, mas ao esforço de comunicação com a sociedade. Para fins de demonstração foram selecionadas as micromobilizações de defesa de identidades, como as feministas, e pela defesa de práticas particulares, nas quais se

${ }^{2}$ Fédération Internacionale de Football Association. 
incluem as marchas das vadias (4) e pela humanização do parto (5). Nessas micromobilizações o repertório é mais diversificado, contendo, além das marchas, apresentações mais criativas, com uso de cores e música, além de ações de caráter disruptivo. Na internet, a comunicação desses grupos tenta conseguir a adesão de novos simpatizantes, mas atua principalmente como reforço dos vínculos entre os indivíduos já mobilizados.

Para empreender essa análise, as micromobilizações serão analisadas a partir da interpretação dos enquadramentos da ação coletiva, tendo como pressuposto que o repertório desses grupos mobilizados é o recurso através do qual se estabelece a comunicação política atualmente, fortemente perpassada pelo ativismo digital.

\section{Confronto, micromobilização e ativismo digital}

A teoria da mobilização política (MP), desenvolvida nos anos 1970 e 1980, tem sido revisitada nos últimos anos para discutir as novas formas de protesto e ação coletiva e oferece alguns elementos importantes para observar o ativismo político contemporâneo. Uma das razões desta volta da MP é a ênfase que dá aos ciclos de mobilizações políticas, com foco nos processos de institucionalização das ações coletivas.

Para Tarrow (2009, p. 18), toda ação coletiva é marcada pelo confronto político (contentious politics). “O confronto político ocorre quando pessoas comuns, sempre aliadas a cidadãos mais influentes, juntam forças para fazer frente às elites, autoridades e opositores." O que desencadeia o confronto é um arranjo contingente de oportunidades e restrições políticas, que informam os atores sociais em disputa sobre como utilizar repertórios de confronto disponíveis para então ampliá-los e criar inovações pontuais. 
Entendendo (com Tilly, 1992) 3 o repertório de confronto como um "conjunto limitado de rotinas que são aprendidas, compartilhadas e executadas através de um processo relativamente deliberado de escolha", Tarrow (2009, p. 65) afirma que ele funciona como um menu de opções disponíveis para a ação, as quais são restritas pelos limites do aprendizado. Aos poucos, partes do repertório se tornam componentes da política convencional: a greve se converte em instituição de barganha coletiva, a demonstração passa a ser regulada por leis que a distinguem de atos criminosos, ocupações de edifícios deixam de ser tratadas como casos de delinquência. Dessa forma, podemos entender as apropriações do repertório de confronto como um elemento performático das ações coletivas e, na medida em que o repertório de confronto é absorvido pelos atores, ele se torna institucionalizado.

Para analisar o confronto, a teoria se vale do conceito de enquadramento. A concepção original é de Snow (1986), que o define como os esforços estratégicos de grupos de pessoas para produzir um entendimento comum sobre o mundo, que venha a legitimar e motivar a ação coletiva. A dimensão estratégica do enquadramento, no entanto, fica mais consciente quando os atores se deparam com adversários (frame contest). Na disputa de enquadramentos (para legitimar o argumento público) entre atores, o Estado e alguns contramovimentos, o mediador principal é a mídia. Enquadrar, mais que interpretar, é criar e atribuir significado pela hierarquia de importância a fatos da realidade em disputa.

Nas micromobilizações que serão analisadas procura-se atualizar a teoria da mobilização política com a entrada em cena de repertórios do ativismo digital, que replicam antigos repertórios no espaço online ao mesmo tempo em que apresentam elemento catalizador de

\footnotetext{
${ }^{3}$ TILLY, Charles. How to detect, describe and explain repertoires of contention, 1992 (texto não publicado, citado por TARROW, 2009, p. 51).
} 
repertório, que são as hashtags. Daí o conceito de micromobilizações parecer promissor nesse sentido.

Elencando uma série de estudos que variam entre a percepção da internet e seus recursos como capazes de aumentar a participação democrática, fortalecer as organizações da sociedade civil e revigorar a democracia, até estudos que além das potencialidades da internet apontam limitações, Maia (2011, p. 69) entende que "a internet não promove automaticamente a participação política e nem sustenta a democracia", o que, segundo a autora, não significa que a internet seja tão somente uma infraestrutura neutra nem que não potencialize alterações entre aqueles que a utilizam com propósitos políticos.

Em artigo sobre os rappers de Curitiba, Prudencio \& Silva Jr. (2013) expõem que muitos destes atores sociais utilizam a internet para interagir e mobilizar parceiros e simpatizantes para ações estéticas e políticas que comunicam no espaço público uma luta por reconhecimento. Ainda de acordo com os pesquisadores estas ações, transformadas em registros audiovisuais, são posteriormente veiculadas em mídias digitais administradas por eles gerando com isso novas interações, cuja circularidade ajuda os grupos de rappers a manter-se em movimento, enquanto suas reivindicações por políticas públicas culturais mais abrangentes não são formuladas pelos organismos governamentais responsáveis pela gestão cultural do município e do estado.

Assim, as mídias sociais digitais, os fóruns e as salas de bate-papo constituem um espaço para acompanhar a "micromobilização". Quase três décadas depois da publicação do artigo de Snow et al (1986), o conceito de micromobilização pode ser estendido, então, às novas formas de mobilização política sem prejuízo à sua formulação original, abrangendo as formas de ativismo digital cujo repertório se constrói como campanhas específicas dentro de ações mais amplas 
de movimentos sociais e/ou outros atores coletivos, com a finalidade de produzir decisão política num curto prazo.

Entende-se então, pensando com Snow \& Benford (2000), que, seja no âmbito do núcleo de um movimento seja entre o movimento e a sociedade civil, a construção, definição e consolidação dos quadros da ação coletiva depende de como os atores: a) negociam um entendimento compartilhado de que uma situação ou condição é problemática e passível de mudança; b) definem problemas e culpados; c) articulam um conjunto alternativo de medidas e estimulam outros a agir em prol da mudança.

Os autores apresentam três conceitos para definir as operações que acontecem no núcleo dos processos de enquadramento orientados para a ação coletiva: enquadramento de diagnóstico, enquadramento de prognóstico e enquadramento motivacional. O primeiro refere-se à identificação de problemas e identificação do adversário; o segundo envolve a articulação de uma proposta de solução para o problema, ou, pelo menos, estratégias para realização do plano; e o terceiro visa motivar ações para a realização de mudanças.

Por isso, parece mais interessante discutir como as micromobilizações empreendem o trabalho de alinhamento de quadros (Snow et al, 1986). Segundo os autores, existem quatro tipos de processos pelos quais os quadros a serem comunicados são alinhados (frame alignment): frame bridging, frame amplification, frame extension; frame transformation.

Frame bridging é a ligação de dois ou mais quadros congruentes, mas ideologicamente desconectados a respeito de um determinado assunto ou problema. Refere-se ao trabalho de relações públicas das mobilizações: conectar as demandas particulares de um grupo com o restante da sociedade. Frame amplification refere-se ao esclarecimento e fortalecimento de um quadro interpretativo sobre um determinado assunto, problema ou conjunto de eventos. É o trabalho de 
apresentar o argumento para além dos já mobilizados. O frame extension pode ser explicado pela expansão das fronteiras do quadro principal (primary framework) protagonizada por um grupo de forma a englobar interesses ou pontos de vistas que nem sempre correspondem aos seus objetivos primários, mas que possuem considerável relevância para potenciais adeptos. É o quadro resultante da troca argumentiva ${ }^{4}$. Por fim, o frame transformation refere-se ao surgimento de um novo quadro que interpreta os acontecimentos e experiências em uma nova chave.

A análise das micromobilizações leva em consideração os seguintes aspectos: a) a identificação de uma campanha específica que a caracterize como micromobilização; b) oportunidades políticas existentes e o estabelecimento de um "nós" contra "eles"; c) os quadros de diagnóstico, prognóstico e motivação; d) o processo de alinhamento de quadros predominante (bridging, amplification, extension, transformation); e e) os quadros construídos na micromobilização.

\section{Micromobilizações e confronto com Estado}

A seguir são apresentadas algumas micromobilizações que estabelecem um confronto com instituições estatais, em que grupos mobilizados dirigem ao sistema político uma demanda específica, atuando através de campanhas para aprovação ou veto de leis ou políticas públicas, ou ainda contra uma decisão de governo.

\footnotetext{
${ }^{4}$ Por questões de espaço, não será possível desenvolver neste artigo a discussão sobre troca argumentativa e deliberação. Isso foi discutido num outro trabalho (PRUDENCIO, K. \& HOSHINO, C., 2014), que procura explorar a efetividade da comunicação política nas manifestações de 2013 no Brasil.
} 
Movimento Passe Livre:

O Movimento Passe Livre se define como "um movimento social autônomo, apartidário, horizontal e independente, que luta por um transporte público de verdade, gratuito para o conjunto da população e fora da iniciativa privada" (TARIFA ZERO, 2014). Basicamente, a ideia da organização é discutir o transporte público nas cidades, protestar por readequações tributárias e, como objetivo principal, adquirir para toda a sociedade o direito à mobilidade. Surgiu em 2005 e, desde 2013, o movimento que mais recebe cobertura nacional da mídia é o de São Paulo, grande responsável pelo início dos protestos de junho de 2013. A micromobilização contra o aumento da passagem é que será analisada, e não o movimento como organização.

O MPL reúne repertório de ação vasto e variado. São vários os protestos de rua, reuniões e assembleias, todos marcados em eventos no Facebook, de onde saem ideias como produção de cartazes, jornais e panfletos, oficinas, manifestações artísticas e debates ou aulas públicas sobre o tema. Entre os produtos estão produções audiovisuais (como vídeos em canais do YouTube), marchinhas e blocos de carnaval - e também ações mais diretas, como pular a catraca em forma de protesto.

Várias hashtags ${ }^{5}$ estão vinculadas ao repertório, mas é curioso notar que o uso dessas palavras-chave é feito na maior parte por indivíduos de fora da organização, sem estarem presentes em páginas ou perfis oficiais. Elas englobam o passe livre em si (\#passelivrejá, \#passelivre, \#tarifazero e \#porumavidasemcatracas, \#queimacatraca, \#pulacatraca, \#descatraca e \#mpl), o aumento da passagem de ônibus em 2013 (\#contraoaumento), críticas a governantes (\#caçaaofortuna e \#ocupacâmaraPoa, ambas de Porto Alegre) e à ação da polícia nas manifestações (\#desmilitarizajá). Notase ainda que boa parte das ações de repertório é formada de apelos à

\footnotetext{
${ }^{5}$ Elas são encontradas tanto no Twitter como no Facebook.
} 
sociedade para mobilizar a causa e tentativas de convencer a população a integrar-se ao movimento. Já as hashtags, na imensa maioria, mostram críticas ou propostas diretas ao Estado.

Por ser um movimento social com alguma organização, é possível esperar que a cada anúncio de aumento na tarifa do transporte público o MPL se manifeste, pois as estruturas de mobilização são mais facilmente acionadas. No caso da mobilização de 2013, o ambiente foi propício e novamente interpretado como oportunidade política para comunicar à sociedade o projeto do passe livre, ainda que a campanha tenha sido especificamente contra o aumento. Nessa interpretação, o adversário, claro, está nos governos municipais, com os quais estabelece o confronto e para onde se dirigem os argumentos.

O repertório nas redes sociais indica que o MPL e seus simpatizantes falavam do aumento da tarifa e associavam a campanha ao projeto mais abrangente do movimento com o uso das hashtags. É possível notar o surgimento de sentidos outros já nessa campanha, principalmente contra a violência policial, que passa também a se constituir como adversário. A micromobilização foi uma reação ao anúncio, mobilizando os membros do movimento contra a decisão das prefeituras.

O perfil no Facebook ${ }^{6}$ foi criado em 18 de junho de 2013, no calor das manifestações. Naquele mês, foram poucas as postagens, com baixa participação nos comentários. Serviu como espaço de convocação para as manifestações de rua e reuniões, para reprodução de notícias sobre os protestos, cartas à presidente e para reforço do enquadramento do protesto contra o aumento como parte da luta mais abrangente pelo passe livre.

\footnotetext{
${ }^{6}$ Disponível em: <https://www.facebook.com/MovimentoPasseLivrempl?fref=ts>. Acesso em: 15 set. 2014. Curiosamente, esse momento representou a retirada do MPL do protagonismo dos protestos de junho de 2013.
} 
Claramente, os quadros de diagnóstico e prognóstico já estavam dados antes mesmo da micromobilização que virou manifestação de rua. O que muda na interação ocorrida no Facebook são os quadros motivacionais: para conseguir adesão, o MPL reforça o quadro de que transporte público é direito e não um mero serviço público.

$\mathrm{Na}$ interação observada nos comentários, o MPL se vê obrigado a contornar o processo de frame extension para garantir o frame brigding: a meta da micromobilização era pelo cancelamento do aumento, mas o surgimento de outros protestos, como o combate ao sistema partidário no Brasil observado nas ruas, acaba por comprometer os outros dois processos de alinhamento (bridging e transformation). Como o processo de frame amplification estava de alguma forma controlado, na ideia do passe livre, a estratégia foi garantir apoio midiático e efetividade política: o aumento não saiu.

Assim, o MPL empreende nas redes sociais um trabalho de comunicação que oscila entre a organização da mobilização e a administração dos contornos dos quadros que fogem ao controle do quadro primário do movimento - passe livre como direito do cidadão - e garante a efetividade da comunicação. Quando o quadro sai do centro e convive com outros processos, o MPL sai de cena, uma vez que alcança seu objetivo político.

\section{Mais Médicos:}

A micromobilização em torno do Mais Médicos é uma articulação da categoria médica contra o programa de mesmo nome, criado pelo governo federal e aprovado pelo Senado em outubro de 2013, no primeiro mandato da presidente Dilma Rousseff (PT). O programa tem o objetivo de dar atenção básica aos municípios com maior vulnerabilidade social, atendidos pelo SUS, com baixa procura pela categoria. Para atender esses municípios o programa abriu vagas 
primeiramente para médicos brasileiros, com meta de aumentar para 2,5 médicos por mil habitantes (um índice que era de 1,8 por mil habitantes). Com o baixo interesse, as vagas foram abertas a médicos estrangeiros, que não precisaram passar pelo atual processo de revalidação do diploma (o exame Revalida), tendo recebido um registro provisório válido apenas para a atuação dentro do programa.

O repertório da campanha contrária ao programa é composto por ações que tentam comunicação política com o Estado, já que é este que tem o poder de interferir ou encerrar o Mais Médicos. A mobilização é da categoria médica, que não pretendeu mobilizar a sociedade. Assim, não houve preocupação com o alinhamento do quadro por bridging.

Fazem parte do repertório protestosas paralisações, que são catalisadas nas redes sociais pelas hashtags \#MaisMédicosFail, \#MaisMédicosNão, \#RevalidaSim, \#foraDilma, \#foraPadilha, \#foraPT, em oposição à hashtag \#MaisMédicos, que é institucional. Nota-se que, nos protestos, paralisações e nas hashtags \#MaisMédicosFail, \#MaisMédicosNão e \#RevalidaSim o enquadramento da classe médica é de reserva de mercado.

A categoria enquadra o problema também como um desvio de atenção governamental, alegando que este enfoca e responsabiliza o profissional, ao invés de gerir melhor a saúde pública e de investir mais em infraestrutura. Já as hashtags \#foraDilma, \#foraPadilha e \#foraPT funcionam com desqualificação do interlocutor, o que inviabiliza o processo de frame extension.

O enquadramento institucional é de que a aplicação do programa constituía uma necessidade, já que havia necessidade de atendimento médico em diversos municípios. A hashtag \#MaisMédicos enquadra também o programa como gestão de saúde pública. 
A micromobilização se dá assim por campanha específica de grupos contrários ao programa, que se valem dos argumentos baseados na formação profissional dos médicos no Brasil, alegando que os estrangeiros não podem atuar no país sem o "revalida". O diagnóstico é fracamente apresentado, reduzindo-se a uma questão corporativa, e o prognóstico é a negação do programa, motivando quadros para a defesa de outra política de saúde pública, mas sem apresentar qual seria.

Nesse episódio, também é possível perceber que a borda do frame primário é ampliada para outras críticas ao governo, como é possível visualizar nas hashtags no Twitter, principal mídia digital da micromobilização. Trata-se de um caso em que o alinhamento de bridging não é realizado, na medida em que as interações nas redes sociais acontecem apenas entre os que se posicionam contrários ao programa, inclusive reforçando o estereótipo do médico/estudante de medicina como representante de uma elite social.

Aqui foi possível perceber que, embora fosse uma campanha específica contra um adversário claro (o governo federal), a micromobilização não é efetiva em termos de comunicação política, pois abriu mão do diálogo com outros grupos (frame extension), resultando na ausência de um quadro de prognóstico claro que posicionasse politicamente a categoria médica para uma negociação com o Estado.

Não Vai Ter Copa:

O Não Vai Ter Copa é uma campanha de protesto contra a realização da Copa do Mundo de 2014 no Brasil, impulsionada por bandeiras como desigualdade social, corrupção e mau uso do dinheiro público. Ela nasceu a partir de diversos coletivos e movimentos, além de ativistas simpáticos à causa e setores da sociedade afetados pela 
Federação Internacional de Futebol (Fifa) e Governo Federal. Uma das críticas tem como alvo a Lei Geral da Copa, a alteração na legislação brasileira com uma série de medidas a serem tomadas durante preparação e realização da Copa das Confederações, em 2013, e da Copa do Mundo. Ela cobre setores como direitos comerciais e uso de marcas registradas, áreas de restrição comercial e vias de acesso, atividades de publicidade, venda de ingressos, condições de acesso e disposições penais (BRASIL, 2012).

O embrião das manifestações data de 2010, com a criação dos chamados Comitês Populares da Copa (COMITÊ POPULAR DA COPA E OLIMPÍADAS, 2014). Eles nascem de forma independente nas 12 cidades-sede e protestam contra este e outros megaeventos. Os comitês, posteriormente reunidos no Portal Popular da $\mathrm{Copa}^{7}$, denunciam irregularidades em obras, gastos excessivos em estádios ou na cidade e ações como desapropriação de moradias e remoção de pessoas em situação de rua próximas às arenas.

A intensificação da micromobilização acontece durante a Copa das Confederações, torneio de menor escala que serve como prévia do mundial e ocorre no próprio país-sede da Copa do Mundo. A exploração da oportunidade política coincidiu com a ida às ruas em junho de 2013, catalisada pelo MPL e adotada por outras causas. Foi por conta desses protestos que surgiu o grito "Não vai ter copa", adotado pela mídia e pelas próprias organizações como nome e objetivo da mobilização. A partir desse momento, a imprensa passa a cobrir ações.

Quando o grito foi incorporado aos protestos, o significado era literal: fazer com que a ida às ruas e outras manifestações populares atrapalhassem a organização do torneio, impossibilitassem certas cerimônias e prejudicassem a realização da Copa do Mundo. Em último caso, o Brasil poderia até mesmo deixar de ser a sede do

$7 \mathrm{O}$ endereço é www.portalpopulardacopa.org.br. 
torneio, caso a FIFA chegasse à conclusão de que a situação no país era imprópria para receber as comitivas. Com a aproximação do torneio, que seria de fato realizado, o "Não Vai Ter Copa" passa a ser um conjunto de protestos que criticam a organização do mundial, mas não buscam mais o cancelamento.

O repertório é semelhante ao apresentado pelo MPL, com menos variantes e algumas especificidades. A movimentação do grupo no Facebook é bastante intensa, com várias páginas nomeadas como "Não Vai Ter Copa" e semelhantes. O foco é um pouco menor no Twitter. As principais hashtags utilizadas são as seguintes: \#NãoVaiTerCopa, \#FIFAGoHome, \#FuckFIFA, \#CopaPraQuem? e \#ForaDilma. Enquanto a primeira é a reprodução do nome dos protestos, as duas seguintes são ataques diretos ao órgão privado que organiza do torneio. O terceiro é uma crítica direta à realização da Copa do Mundo. Por fim, a última hashtag surge em conjunto com as anteriores e é um protesto contra o governo, que efetuou a candidatura e responsabilizou-se pelo campeonato. O \#VaiTerCopaSim também é visto com frequência, mas se trata de movimento de oposição não organizado que usa bastante da ironia para afirmar que os protestos não serão efetivos, sem apresentar politicamente uma posição de disputa.

O quadro do Não Vai Ter Copa começa, então, a se produzir, nos protestos realizados durante a Copa das Confederações, mesmo que a mobilização tenha surgido antes. Isso significa que o torneio de 2013 é explorado como oportunidade política, confirmando o que Tarrow (2009) e Snow \& Benford (2000) sugerem para a mobilização de quadros. Mas diferentemente do Mais Médicos e do MPL, o Não Vai Ter Copa consegue o alinhamento por amplification, encontrando ressonância em outras mobilizações e transformando a Copa do Mundo no mote contra o governo de Dilma Rousseff. 
Isso significa que o quadro de diagnóstico (a Copa é um problema criado pelo governo) desdobra-se no quadro de prognóstico (governante deve ser afastada), motivados pelos argumentos iniciais de irregularidades no trato das verbas públicas. Esses quadros resultam no processo de frame amplification baseado no processo de frame bridging, identificando-se com outros grupos que também bradavam o \#ForaDilma.

Assim como a campanha do Mais Médicos, o Não Vai Ter Copa também não estabeleceu interlocução política com o seu opositor, o que comprometeu a micromobilização em termos de comunicação política.

Tabela 1. Alinhamento de quadros nas micromobilizações e confronto com o Estado

\begin{tabular}{|c|c|c|c|}
\hline Micromobilização & Marcas do Repertório & $\begin{array}{l}\text { Alinhamento } \\
\text { de Quadros }\end{array}$ & Enquadramento \\
\hline MPL & $\begin{array}{l}\text { \#passelivrejá, \#passelivre, } \\
\text { \#tarifazero, } \\
\text { \#porumavidasemcatracas, } \\
\text { \#queimacatraca, } \\
\text { \#pulacatraca, \#descatraca, } \\
\text { \#mpl, \#demilitarizajá }\end{array}$ & $\begin{array}{l}\text { Controle de } \\
\text { Extension } \\
\text { Garantia de } \\
\text { Bridging }\end{array}$ & $\begin{array}{l}\text { Direito à } \\
\text { mobilidade }\end{array}$ \\
\hline $\begin{array}{l}\text { Não Vai Ter } \\
\text { Copa }\end{array}$ & $\begin{array}{l}\text { \#NãoVaiTerCopa, } \\
\text { \#FIFAGoHome, \#FuckFIFA, } \\
\text { \#CopaPraQuem?, \#ForaDilma }\end{array}$ & $\begin{array}{l}\text { Amplification } \\
\text { (com } \\
\text { bridging) }\end{array}$ & $\begin{array}{l}\text { Desperdício de } \\
\text { recursos } \\
\text { públicos }\end{array}$ \\
\hline & \#VaiTerCopaSim & & \\
\hline Mais Médicos & $\begin{array}{l}\text { \#ForaPadilha, \#ForaDilma, } \\
\text { \#ForaPT, \#MaisMédicos }\end{array}$ & $\begin{array}{l}\text { Amplification } \\
\text { (sem } \\
\text { bridging) }\end{array}$ & $\begin{array}{l}\text { Incompetência } \\
\text { ou despreparo } \\
\text { dos médicos } \\
\text { estrangeiros }\end{array}$ \\
\hline
\end{tabular}

Fonte: a autora 


\section{Micromobilizações e confronto entre grupos}

Essas micromobilizações caracterizam-se pela apresentação de uma troca argumentativa que a teoria da mobilização política chama de disputa de enquadramentos. São confrontos que não se dirigem diretamente ao Estado, mas empreendem esforços para alterar o significado dos objetos de discussão. Duas marchas foram selecionadas para apresentar esse tipo de confronto: a Marcha do Parto em Casa ou pela humanização do parto; e a Marcha das Vadias.

\section{Marcha do Parto em Casa:}

A Marcha do Parto em Casa, realizada em 2012, e Marcha pela Humanização do Parto, realizada em 2013, dão visibilidade a questões relacionadas à assistência ao parto, comuns em ambientes como os consultórios médicos e grupos de apoio às gestantes, mas pouco debatidas em ambientes públicos ${ }^{8}$.

Diante desse cenário, grupos de mulheres e casais realizam ações em defesa da humanização do parto em dezenas de cidades brasileiras. Segundo eles, um parto humanizado não é apenas ou qualquer parto por via vaginal, conhecido no Brasil como parto normal, mas aquele realizado em condições adequadas e que respeite as decisões da mulher. Essa representação discursiva está em confronto com a visão predominante na classe médica sobre a assistência ao parto e ao recém-nascido, para quem o parto é um evento com potenciais riscos e que deve ser assistido com todos os recursos tecnológicos disponíveis.

O envolvimento dos manifestantes em relação à defesa do parto natural é declarado em blogs, listas de discussão e nas redes sociais.

${ }^{8}$ O Brasil é considerado o país recordista mundial na proporção de nascimentos por cesariana. Em 2010, mais de 50\% dos brasileiros nascessem por via cirúrgica (Ministério da Saúde, 2010), enquanto a recomendação da Organização Mundial da Saúde é que esse percentual não ultrapasse os $15 \%$. 
Com o suporte desses meios eletrônicos, os grupos construíram significados comuns que foram expostos durante as manifestações de rua.

O enquadramento dado ao tema pelos grupos mobilizados foi mais bem delineado após a sequência de ações desencadeadas a partir de junho de 2012, em confronto dos defensores do parto em casa com o Conselho Regional de Medicina do Rio de Janeiro (Cremerj).

Pode-se considerar que a micromobilização consegue visibilidade quando o vídeo "Parto de Sabrina - Nascimento de Lucas" torna-se viral na internet, com mais de dois milhões de visualizações ${ }^{9}$. No dia 10 de junho de 2012, o vídeo foi tema de reportagem na revista semanal Fantástico, da Rede Globo, que é um dos programas de maior audiência da televisão brasileira. A matéria "Parto Humanizado Domiciliar causa polêmica entre profissionais da saúde" ${ }^{10}$ expõe que o Conselho Nacional de Enfermagem aprova a prática, com ressalvas, mas que o Conselho Federal de Medicina, a Federação Brasileira de Ginecologia e Obstetrícia e o Ministério da Saúde desaprovam.

Em seguida, doulas ${ }^{11}$ criaram no Facebook a página do evento Marcha do Parto em Casa, pela qual organizaram a mobilização. Em quatro dias foram mobilizadas pessoas em 30 cidades, de 17 estados, em todas as regiões do Brasil. Foram criadas também páginas de eventos locais e de grupos de organização em que as internautas organizaram a Marcha em suas cidades.

As imagens das manifestações nas ruas das cidades em que houve maior aglomeração de pessoas (centenas ou dezenas) eram de

\footnotetext{
${ }^{9}$ Em janeiro de 2014, um ano e 11 meses após a sua publicação, o vídeo contava com 7.310.775 - continuando a ser um dos vídeos de parto mais vistos no Youtube. ${ }^{10}$ Disponível em: <http://globotv.globo.com/rede-globo/fantastico/v/partohumanizado-domiciliar-causa-polemica-entre-profissionais-da-area-desaude/1986583/>. Acesso em: 10 de jan. 2014.

${ }^{11}$ Mulheres que dão suporte físico e emocional a outras mulheres antes, durante e após o parto. Não são parteiras.
} 
mulheres com filhos, gestantes (muitas de barrigas expostas e pintadas) e alguns homens que carregavam cartazes, faixas, megafones. Entre as frases mais presentes durante a manifestação estiveram: "Não preciso de Conselho para parir", "Meu parto, minhas escolhas", "Eu decido", "Deixe eu dar a luz no meu canto" e "Meu corpo, meu parto, minhas escolhas". Várias crianças usavam camisetas escritas: "Eu nasci em Casa". Essas expressões também foram usadas como hashtags nas redes sociais. No Rio de Janeiro os manifestantes foram até a frente do Cremerj e em São Paulo até a frente do Cremesp em protesto.

Os argumentos usados pelas mulheres que defendem o parto humanizado, na rede social Facebook, foram capazes de construir um cenário que as levou para as ruas e atraiu a atenção da mídia. A ampliação do conflito entre os grupos mobilizados e o Conselho de Medicina ampliou a discussão sobre o poder de escolha da mulher sobre o parto e temas correlatos, como a violência obstétrica.

O objetivo de ressignificar culturalmente o parto, com a exposição de imagens (vídeo do parto domiciliar), de campanhas e da repercussão midiática fez com que de parto em casa, a marcha se convertesse numa micromobilização pela humanização do parto, como resultado do frame bridging e do frame extension. O quadro humanização do parto consegue comunicar a diversos segmentos, desde o que defende o parto domiciliar sem médico até o que aceita um parto cirúrgico humanizado (sem violência obstétrica).

Dessa forma, entende-se que o alinhamento de quadros produziu frame transformation, pois, além de incorporar outros sentidos para a marcha, ampliou o debate para a sociedade, antes restrito aos círculos médicos. E ainda apresenta uma possibilidade de alcançar o sistema político na forma de garantia do direito de escolher o parto. 
Marcha das Vadias:

A Marcha das Vadias, mobilização de cunho feminista, articulada por meio de redes sociais, foi criada em abril de 2011, no Canadá (SlutWalk), depois que um policial falou que as mulheres deveriam evitar se vestir como vadias (sluts) para não serem vítimas de abuso sexual no campus da Universidade de York, em Toronto.

As ativistas visam desconstruir a ideia de que atos violentos, sejam eles físicos ou verbais, possam ser justificados devido a algum comportamento ou atitude da mulher (roupas, expressões, olhares). Nas manifestações e nas redes sociais são constantemente usadas expressões cunhadas por pesquisadoras e escritoras ligadas aos movimentos feministas, como, por exemplo: "meu corpo, minhas escolhas" (\#meucorpominhasescolhas é umas das hashtags mais utilizadas pelas ativistas).

As falas, gestos, roupas e cartazes utilizados durante as manifestações fazem um enfrentamento à cultura religiosa, especialmente a católica, e às tradições familiares (família patriarcal). E, apesar da relação direta com as questões levantadas pelos movimentos feministas, a Marcha não é promovida por grupos feministas organizados.

Segundo o site da Marcha em Toronto, a manifestação já foi realizada em mais de 200 países. No Brasil, a primeira Marcha das Vadias aconteceu em junho de 2011, em São Paulo, com a participação de aproximadamente 300 manifestantes. Outras edições foram realizadas no mês de junho em 2012 e 2013, em diversas cidades. Estima-se que em 2013, três mil pessoas participaram da Marcha em Brasília.

As micromobilizações da Marcha das Vadias, ao projetar um adversário cultural, o machismo, empreendem um trabalho de comunicação com a sociedade, no sentido de mobilizar quadros para 
o reconhecimento de um direito, representado na palavra de ordem "meu corpo, minhas escolhas". Assim, produz um alinhamento de bridging com vistas ao alinhamento de amplification, pois, na medida em que diagnosticam o problema da violência contra a mulher como resultado de uma cultura machista, reconhecem os ganhos jurídicos alcançados, enquadram a luta como mudança de mentalidade, o que não se resolve com um processo de decisão política de curto prazo.

Esse quadro não é construído pelo processo de frame extension, ainda que haja discussões entre grupos feministas que apoiam o protesto, porque o quadro inicial é mantido, sem grandes alterações, com proximidade entre quadro de diagnóstico e prognóstico.

Tabela 2. Alinhamento de quadros nas micromobilizações e confronto entre grupos

\begin{tabular}{|c|c|c|c|}
\hline Micromobilização & Repertório & $\begin{array}{l}\text { Alinhamento de } \\
\text { quadros }\end{array}$ & Enquadramento \\
\hline $\begin{array}{l}\text { Marcha pela } \\
\text { Humanização do } \\
\text { Parto }\end{array}$ & $\begin{array}{l}\text { \#MeuPartoMinhasescolhas, } \\
\text { \#eudecido }\end{array}$ & $\begin{array}{l}\text { Transformation: } \\
\text { de Marcha pelo } \\
\text { Parto em Casa à } \\
\text { Humanização } \\
\text { do Parto. }\end{array}$ & $\begin{array}{l}\text { Parto como } \\
\text { momento } \\
\text { pessoal e não } \\
\text { como } \\
\text { procedimento } \\
\text { médico }\end{array}$ \\
\hline $\begin{array}{l}\text { Marcha das } \\
\text { Vadias }\end{array}$ & \#MeuCorpoMinhasEscolhas & $\begin{array}{l}\text { Bridging e } \\
\text { amplification } \\
\text { (mantém } \\
\text { quadro inicial) }\end{array}$ & $\begin{array}{l}\text { Autonomia } \\
\text { feminina sobre } \\
\text { o corpo. }\end{array}$ \\
\hline
\end{tabular}

Fonte: a autora

\section{Considerações finais}

O que foi possível perceber nas mobilizações apresentadas é que a oportunidade política - a leitura produzida a partir do cenário das forças em disputa - muda o repertório do ativismo digital, cujo catalizador (mas não substância) está nas hashtags, em torno das 
quais circulam os quadros da mobilização. Se a mobilização era contra o programa Mais Médicos, cujo quadro inicial se construiu em torno de uma oposição corporativa, ela se expande para uma insatisfação generalizada contra o governo, o que também pôde ser observado no Não Vai Ter Copa e nos protestos do MPL. No caso das mobilizações feministas, o quadro inicial é mantido e reforçado pelo repertório, apresentando uma comunicação que opera ao mesmo tempo como mobilização dos quadros internos e como ponte com a sociedade - característica do processo de frame amplification -, sem a polarização encontrada nas micromobilizações que têm no Estado ou governo seu adversário principal.

Assim, o confronto político apresenta nos primeiros casos uma possibilidade de efetividade maior em termos de comunicação política: a polarização entre adversários em torno de programas ou eventos coloca mais claramente os problemas para a decisão política. No segundo caso, a mobilização funciona como criadora de vínculos entre os mobilizados, num trabalho de comunicação de longo prazo.

No primeiro grupo, nota-se a convergência do quadro de oposição ao governo, sintetizado nas hashtags \#ForaDilma e \#ForaPT, ainda que ele não tenha sido uma estratégia desta ou daquela mobilização. As micromobilizações Não Vai Ter Copa e Mais Médicos não apresentam disputa clara de enquadramento, porque o alinhamento foi por amplification. No primeiro caso a partir de um processo de frame brigding inicial e no segundo, sem esse processo, restrito apenas à manutenção do argumento que motivou a micromobilização. 0 prognóstico fraco do Não Vai Ter Copa compromete o alinhamento por frame transformation. Dessa forma, apenas o MPL consegue estabelecer uma comunicação política efetiva, na medida em que faz uma concessão temporária no seu objetivo principal e especifica o objetivo da micromobilização. 
As micromobilizações do segundo grupo interagem mais com a mídia de massa, o que evidencia a sua importância para a comunicação dos ativistas com a sociedade. A Marcha do Parto é a única que realiza frame transformation, uma vez que a troca argumentativa realizada no alinhamento por frame extension permite abranger outros posicionamentos para além do argumento inicial do parto domiciliar, com a ideia de humanização do parto. Apresenta uma disputa clara de enquadramento com os conselhos de medicina. A Marcha das Vadias não altera o quadro inicial, realizando o alinhamento por frame bridging e frame amplification, com a garantia do cumprimento da lei - sem a necessidade de estabelecer comunicação política.

\section{Referências}

BRASIL. Lei $\mathrm{n}^{\circ} 12.663$, de 5 de junho de 2012. Disponível em: <http://www.planalto.gov.br/ccivil_03/_ato2011-2014/2012/Lei/L12663.htm>. Acesso em 30 de julho de 2014.

COMITÊ POPULAR DA COPA E OLIMPÍADAS. Histórico de atividade. Disponível em <http://comitepopulario.wordpress.com/historico-de-atividades>. Acesso em 30 de julho de 2014.

DOWBOR, M; SZWAKO, J. Respeitável público... Performance e organização dos movimentos antes dos protestos de 2013. In: Novos Estudos Cebrap, n. 97, novembro de 2013, p. 43-55.

MAIA, Rousiley Celi Moreira. Internet e esfera civil: limites e alcances da participação política. In: GOMES, Wilson; MAIA, Rousiley C. M.; MARQUES, Francisco J. A. (Orgs.). Internet e participação política no Brasil. Porto Alegre: Sulina, 2011.

MOVIMENTO PASSE LIVRE. Apresentação. Disponível em <http://saopaulo.mpl.org.br/apresentacao/>. Acesso em 30 de julho de 2014.

PRUDENCIO, K; HOSHINO, C. Incomunicação política: os limites do ativismo digital nas manifestações de junho de 2013 no Brasil. 2014 (No prelo).

PRUDENCIO, K; SILVA JR, J. G. A comunicação política das micromobilizações na internet: uma proposta metodológica a partir da observação do hip hop em Curitiba Trabalho apresentado ao Grupo de Trabalho Comunicação e Política do XXIII Encontro Anual da Compós, Universidade Federal do Pará, Belém, 27 a 30 de maio de 2014.

PRUDENCIO, Kelly Cristina de Souza. Mobilizar é comunicar estruturas interpretativas: apontamentos para discussão e pesquisa sobre a comunicação dos atores coletivos. In: Castilho, A; Rocha, D; Macedo, R. Comunicação política na esfera pública: democracia, eleições e cidadania no Brasil. Capivari: Nova Consciência, 2013. 
RUCHT, D. The quadruple 'A': media strategies of protest movements since the 1960s. In: VAN DE DONK, Wim; LOADER, Brian D.; NIXON, Paul G.; RUCHT, Dieter. Cyberprotest. New media, citizens and social movements. London: Routledge, 2004.

SNOW, David A. BENFORD, Robert D. Framing Processes and Social Movements: An Overview and Assessment. Annual Review of Sociology, v. 26, 2000, pp. 611-639.

SNOW, David A.; ROCHFORD, E. Burke; WORDEN, Steven K.; BENFORD, Robert D. Frame Alignment Processes, Micromobilization, and Movement Participation. American Sociological Review, v.51, n. 4, 1986, pp. 464-481.

TARIFA ZERO. Movimento Passe Livre. Disponível em <http://tarifazero.org/mpl/>. Acesso em 30 de julho de 2014.

TARROW, Sidney. o poder em movimento. Movimentos sociais e confronto político. Petrópolis: Vozes, 2009.

COMPOIITICA ASSOCIACÃO BRASILEIRA DE PESQUISADORES EM COMUNICACÅO E POLÍTICA

Presidente: Alessandra Aldé (UERJ)

Vice-Presidente: Luis Felipe Miguel (UnB)

Secretário Executivo: Francisco Jamil Marques (UFC)

Editoras-Chefes:

Alessandra Aldé (UERJ) e Maria Helena Weber (UFRGS)

Editores Executivos:

Edna Miola (UFS), Fernanda Sanglard (UERJ), Rafae

Cardoso Sampaio (UFMG) e Viktor Chagas (UFF)

Revisoras:

Fernanda Sanglard (UERJ) e Isabele Mitozo (UFPR)

<http://compolitica.org/revista>
A Revista Compolítica é uma revista eletrônica da Associação Brasileira de

Pesquisadores em Comunicação e Política. Com periodicidade semestral, sua proposta é difundir a produção acadêmica relacionada às interfaces desses campos de estudo.

Ao citar este artigo, utilize a seguinte referência bibliográfica

PRUDÊNCIO, Kelly. Micromobilizações, alinhamento de quadros e comunicação política. In: Revista Compolítica, n. 4, vol. 2, ed. agosto-dezembro, ano 2014. Rio de Janeiro: Compolítica, 2014. 
